\title{
Modified UH Model: Constitutive Modeling of Overconsolidated Clays Based on a Parabolic Hvorslev Envelope
}

\author{
Yangping Yao'; Zhiwei Gao'; Jidong Zhao ${ }^{3}$; and Zheng Wan ${ }^{4}$
}

\begin{abstract}
Most clays, either naturally deposited or man-made, possess a certain degree of overconsolidation owing to tamping, cyclic loading, erosion, excavation, and/or changes in groundwater tables. An easy-to-use constitutive model for overconsolidated clays is useful for relevant engineering applications. In this paper, a simple model is proposed for overconsolidated clays based on the unified-hardening (UH) model. To evaluate the potential peak stress ratio of overconsolidated clays, a parabolic Hvorslev envelope rather than a straight envelope (used in the original UH model) is adopted. The proposed parabolic Hvorslev envelope passes through the origin of the mean stress-deviatoric stress plane. It has a slope of 3 as the overconsolidation ratio (OCR) approaches infinity and intersects with the critical state line as the OCR reaches unity. This modification leads to more realistic predictions for highly overconsolidated clays than does the original UH model with a straight Hvorslev envelope and is consistent with the critical state soil mechanics in which the higher peak stress ratio in overconsolidated clays is a result of interlocking (or dilatancy) rather than cohesion. The modified UH model retains the same parameters as those in the modified Cam-clay model. Reasonable agreement between the model predictions and experimental data demonstrates that the modified model is capable of addressing the fundamental behavior of overconsolidated clays. The present model is developed for reconstituted clays with an isotropic fabric. The potential improvement of the model, taking into account anisotropy and structural effects, is discussed. DOI: 10.1061/(ASCE)GT.1943-5606.0000649. () 2012 American Society of Civil Engineers.
\end{abstract}

CE Database subject headings: Clays; Overconsolidated soils; Constitutive models.

Author keywords: Clay; Overconsolidation; Critical state; Unified hardening; Hvorslev envelope.

\section{Introduction}

Owing to processes associated with tamping, cyclic loading, erosion, excavation, and/or changes in groundwater tables, most clays encountered in practical engineering may have experienced a consolidation pressure higher than the current one and, hence, exhibit a certain degree of overconsolidation. Unlike normally consolidated clay, overconsolidated soil may normally possess a peak strength with a postpeak strain softening. Accurate characterization of the behavior of overconsolidated clays is of great importance in a wide range of engineering applications, including slope stabilization, foundation design, and embankment construction. Therefore, it is desirable to have a simple constitutive model that is easy to use for practicing engineers when addressing the behavior of overconsolidated clays and relevant geostructures. The Cam-clay models have been well received in modeling the fundamental behavior

\footnotetext{
${ }^{1}$ Professor, Dept. of Civil Engineering, Beihang Univ., Beijing, China (corresponding author). E-mail: ypyao@buaa.edu.cn

${ }^{2}$ Ph.D. Candidate, Dept. of Civil and Environmental Engineering, Hong Kong Univ. of Science and Technology, Hong Kong Special Administrative Region, China.

${ }^{3}$ Assistant Professor, Dept. of Civil and Environmental Engineering, Hong Kong Univ. of Science and Technology, Hong Kong Special Administrative Region, China.

${ }^{4} \mathrm{Ph} . D$. Candidate, Dept. of Civil Engineering, Beihang Univ., Beijing, China.

Note. This manuscript was submitted on February 24, 2011; approved on October 18, 2011; published online on June 15, 2012. Discussion period open until December 1, 2012; separate discussions must be submitted for individual papers. This paper is part of the Journal of Geotechnical and Geoenvironmental Engineering, Vol. 138, No. 7, July 1, 2012. (C)ASCE, ISSN 1090-0241/2012/7-860-868/\$25.00.
}

of clays (Roscoe et al. 1958, 1963; Schofield and Wroth 1968; Roscoe and Burland 1968; Muir Wood 1990). They can capture the behavior of normally consolidated and lightly overconsolidated clays fairly well; however, they fail to reproduce the experimental behavior of highly overconsolidated clays with satisfaction. This is mainly because the Cam-clay models are based on the classical plasticity theory (Hill 1950), and they do not allow plastic deformation to occur inside the yield surface (e.g., Pender 1978; Yu 1998). However, experimental observations show that plastic deformation may occur before the stress state reaches the yield surface and when the soil behavior does not show an obvious transition from being perfectly elastic to elastoplastic (e.g., Pestana et al. 2002; Prashant and Penumadu 2004).

A variety of approaches have been proposed in the past in an attempt to address the issue of overconsolidated clays more satisfactorily. Among the early studies is the nested surface concept proposed by Mróz and coworkers (Mróz 1967; Mróz et al. 1978). This model featured a series of nested configuration surfaces associated with different state variables and the accuracy of model prediction depends on the number of configuration surfaces used. This work has inspired some further developments such as the bounding surface concept (Dafalias and Popov 1977; Dafalias 1986) and the subloading surface concept (Hashiguchi 1978, 1980; Hashiguchi and Chen 1998). It is assumed in these subsequent models that plastic deformation can occur inside a reference surface. A number of models have been subsequently developed based on these concepts, especially for overconsolidated clays (e.g., Mróz et al. 1979; Dafalias and Herrmann 1986; Whittle and Kavvadas 1994; Gajo and Muir Wood 2001; Hashiguchi and Collins 2001; Ling et al. 2002; Nakai and Hinokio 2004; Dafalias et al. 2006). However, a common drawback of most of these models lies in the difficulty 
in calibrating some of the model parameters through available laboratory means, and more often their values must be determined through a trial-and-error approach. Indeed, this is not particularly convenient for practicing engineers to use in practical designs and analyses.

In this paper, a simple model for overconsolidated clays is proposed based on a previous model developed by the writers (Yao et al. 2009) — the unified-hardening (UH) model. Essentially, in the new UH model the straight Hvorslev envelope used in the original UH model is replaced by a parabolic one. Although the use of a straight Hvorslev envelope in the original UH model is sufficient for most practical applications, it may cause some unrealistic implications. For instance, prediction by the original $\mathrm{UH}$ model for an overconsolidated clay may result in a peak stress ratio $q / p$ that is greater than 3 (where $p$ and $q=$ effective mean stress and deviatoric stress, respectively). Thus, considerable cohesion has to be considered in the clay to sustain the tensile stress. This may be in contradiction with the critical soil mechanics wherein the higher peak stress ratio for overconsolidated clays is understood as a result of dilatancy rather than cohesion (Schofield 2006). This drawback can be effectively eliminated by adopting a parabolic Hvorslev envelope rather than a straight line. Meanwhile, as will be demonstrated, an accompanying advantage of this replacement would be the reduced number of model parameters that have to be introduced in the model. Indeed, in the modified model the identical set of parameters as used in Cam-clay models may be used (Roscoe et al. 1958, 1963; Roscoe and Burland 1968) to characterize the behavior of clays with relatively high overconsolidation ratios (OCRs). The model performance is benchmarked by comparison with test results on Kaolin clay (Banerjee and Stipho 1978, 1979).

\section{Modified UH Model for Overconsolidated Clays}

The new model for overconsolidated clays is based on the original UH model proposed by Yao et al. (2009). A brief description of this model may be helpful for the subsequent model description. The original UH model has been formulated with the help of a current yield surface and a reference yield surface, the origin of which can be found in the subloading surface concept (Hashiguchi 1978, 1980). The major features that differentiate the original UH model from other subloading surface models is the introduction of a $\mathrm{UH}$ parameter $H$, a potential peak stress ratio $M_{f}$, and a transformed stress tensor $\widetilde{\sigma}_{i j}$ based on the spatial mobilized plane (SMP) criterion, which will be elaborated subsequently, along with the derivation of the parabolic Hvorslev envelope and the modified UH model.

\section{Current/Reference Yield Surfaces and the UH Parameter}

The current yield surface in the UH model is assumed to be similar to the yield surface of the modified Cam-clay model, always passing through the current stress point $A(p, q)$ as shown in Fig. 1 . Associated with this surface is the UH parameter $H$. The expression for the current yield surface can be expressed as

$$
f=\ln \frac{p}{p_{x}}+\ln \left(1+\frac{q^{2}}{M^{2} p^{2}}\right)=0
$$

or

$$
f=\ln \frac{p}{p_{x 0}}+\ln \left(1+\frac{q^{2}}{M^{2} p^{2}}\right)-\frac{1}{c_{p}} \int d H=0
$$

where $p_{x}=$ intersection of the current yield surface with the $p$ axis; $p_{x 0}=$ initial value of $p_{x}$ when the plastic volumetric strain is $\varepsilon_{v}^{p}=0$

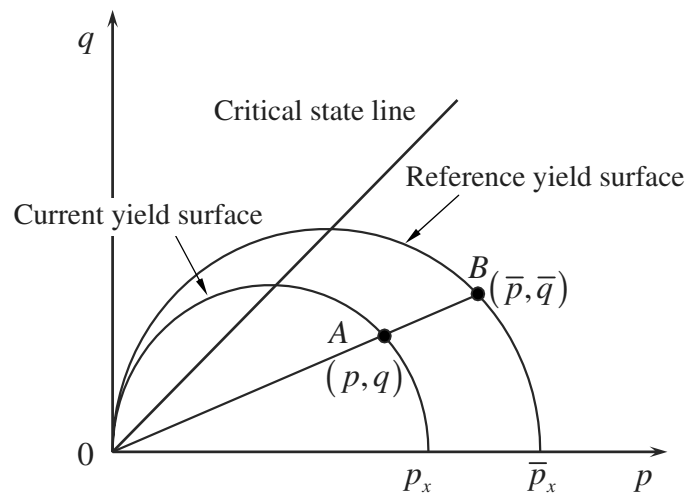

Fig. 1. Current yield surface and the reference yield surface

and $H=0 ; M=$ stress ratio measured at the critical state in triaxial compression; and $c_{p}=(\lambda-\kappa) /\left(1+e_{0}\right)$, in which $\lambda, \kappa$, and $e_{0}=$ compression index, swelling index, and initial void ratio, respectively. An associated flow rule defined by the current yield surface is used in the original UH model.

The UH parameter $H$ for overconsolidated clays (Yao et al. 2009 ) is defined as a function of the current stress ratio, the plastic volumetric strain, and the potential failure stress ratio $M_{f}$ (its determination will be elaborated in conjunction with the Hvorslev envelope in the subsequent subsection) as follows:

$$
H=\int d H=\int \frac{M_{f}^{4}-\eta^{4}}{M^{4}-\eta^{4}} d \varepsilon_{v}^{p}=\int \frac{1}{\Omega} d \varepsilon_{v}^{p}
$$

where $d \varepsilon_{v}^{p}=$ plastic volumetric strain increment and

$$
\Omega=\frac{M^{4}-\eta^{4}}{M_{f}^{4}-\eta^{4}}
$$

The hardening parameter $H$ controls the rate of hardening and softening of the current yield surface during the deformation of the soil.

A reference yield surface identical to the yield surface of the modified Cam-clay model is used. The reference stress point $B(\bar{p}, \bar{q})$ lies on the reference yield surface and is defined according to a radial mapping rule such that it has the same stress ratio as the current stress point: $\eta=\bar{q} / \bar{p}=q / p$ (see Fig. 1). The expression for the reference yield surface can be written as

$$
\bar{f}=\ln \frac{\bar{p}}{\bar{p}_{x}}+\ln \left(1+\frac{\bar{q}^{2}}{M^{2} \bar{p}^{2}}\right)=0
$$

or

$$
\bar{f}=\ln \frac{\bar{p}}{\bar{p}_{x 0}}+\ln \left(1+\frac{\bar{q}^{2}}{M^{2} \bar{p}^{2}}\right)-\frac{1}{c_{p}} \int d \varepsilon_{v}^{p}=0
$$

where $\bar{p}_{x}=$ intersection of the reference yield surface with the $p$ axis; $\bar{p}_{x 0}=$ constant and corresponds to the length of the major axis of the reference yield surface at the initial state when $\varepsilon_{v}^{p}=0$; and $\bar{p}_{x 0}$ is also equal to the preconsolidation pressure $p_{c}$ of overconsolidated clays under an initially isotropic compression condition $\left(\eta_{0}=\bar{\eta}_{0}=0\right)$.

To facilitate the model formulation, an overconsolidation parameter, $R$, which essentially represents the ratio of the size between the current yield surface and the reference yield surface, is defined as follows:

$$
R=\frac{p}{\bar{p}}=\frac{q}{\bar{q}}
$$


Substitution of Eq. (7) into Eq. (6) leads to

$$
R=\frac{p}{\bar{p}_{x 0}}\left(1+\frac{\eta^{2}}{M^{2}}\right) \exp \left(-\frac{\varepsilon_{v}^{p}}{c_{p}}\right)
$$

\section{Transformed Stress Method}

The Cam-clay models with extended von Mises (or DruckerPrager) failure criterion (Drucker and Prager 1952) have been known to be suitable for triaxial compression conditions only and cannot adequately tackle problems in a general three-dimensional (3D) stress space because this criterion gives a failure (or critical state) stress ratio $(q / p)$ independent of the intermediate principal stress ratio defined by Habib (1953) (see also, Bishop 1971) $b=\left(\sigma_{2}-\sigma_{3}\right) /\left(\sigma_{1}-\sigma_{3}\right)$, with $\sigma_{1}, \sigma_{2}$, and $\sigma_{3}$ being the major, intermediate, and minor principal stresses, respectively. For soils, the failure (or critical state) stress ratios measured in triaxial compression $(b=0)$ and extension $(b=1)$ are typically different (e.g., Dafalias and Herrmann 1986; Yao et al. 2004; Gao et al. 2010). Wroth and Houlsby (1985) suggested that the incorporation of more general failure criteria with Cam-clay models such as the SMP criterion (Matsuoka and Nakai 1974) or the Lade's criterion (Lade and Duncan 1975) may partially solve the problem. Some subsequent investigations has been carried out along this line of research (see Yao et al. 1999; Yao and Sun 2000, Yao et al. 2007). In particular, an approach of transformed stress space has been used in these studies. In this paper, the following transformed stress tensor based on the SMP criterion is used (as illustrated in Fig. 2):

$$
\tilde{\sigma}_{i j}=p \delta_{i j}+\frac{q^{*}}{q}\left(\sigma-p \delta_{i j}\right)
$$

where $\delta_{i j}=$ Kronecker's delta and

$$
q^{*}=\frac{2 I_{1}}{3 \sqrt{\left(I_{1} I_{2}-I_{3}\right) /\left(I_{1} I_{2}-9 I_{3}\right)}-1}
$$

where $I_{1}\left(=\sigma_{1}+\sigma_{2}+\sigma_{3}\right), \quad I_{2}\left(=\sigma_{1} \sigma_{2}+\sigma_{2} \sigma_{3}+\sigma_{1} \sigma_{3}\right), \quad$ and $\left(I_{3}\left(=\sigma_{1} \sigma_{2} \sigma_{3}\right)\right)=$ first, second, and third invariants of the stress tensor $\sigma_{i j}$. With the replacement of the real stress tensor $\sigma_{i j}$ by the transformed stress tensor $\tilde{\sigma}_{i j}$, the original UH model can be readily generalized to the $3 \mathrm{D}$ stress space.

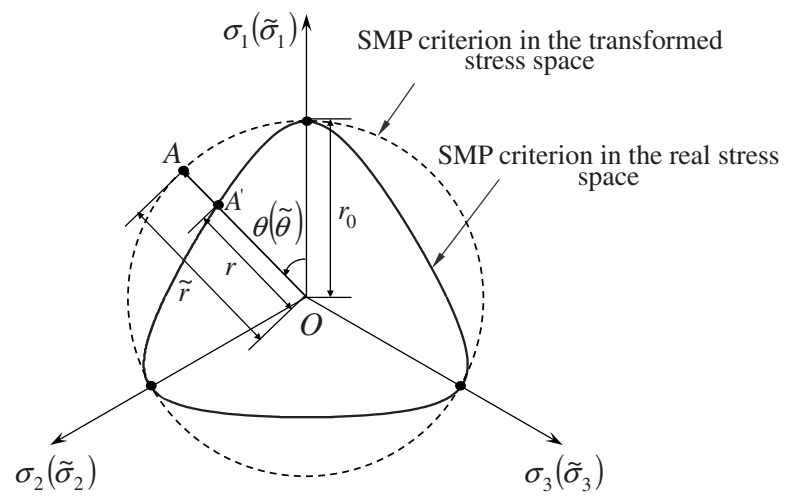

Fig. 2. Illustration of the transformed stress method

\section{Parabolic Hvorslev Envelope and Potential Stress Ratio}

We introduce a new potential peak stress ratio $M_{f}$ to represent the potential capacity of overconsolidated clays to resist shear under the current stress state and density. The stress ratio will play an important role in describing the plastic hardening and failure of overconsolidated clays. In Yao et al. (2009), $M_{f}$ is defined by a straight Hvorslev envelope that intersects the critical state line at $p=\bar{p}$ in the $p-q$ plane (shown as the dash line CD in Fig. 3). The vertical line passing the current (mean) stress $p$ with the straight Hvorslev envelope at point $E$ is denoted as the intersection point. The stress ratio at $E$ has been defined as the potential peak stress ratio $M_{f}$ in the original $\mathrm{UH}$ model:

$$
M_{f}=\left(\frac{1}{R}-1\right)\left(M-M_{h}\right)+M
$$

where $M_{h}=$ slope of the Hvorslev envelope in the $p-q$ plane Fig. 3. While the use of such a simple straight Hvorslev envelope is sufficient for many applications, it may give rise to an unreasonably high peak stress ratio for highly overconsolidated clays. For example, when the value of $R$ approaches zero (or the OCR reaches infinity), the potential peak stress ratio $M_{f}$ also reaches infinity according to Eq. (11). This indicates that $M_{f}$ may be greater than 3.0 for a highly overconsolidated clay. Under the triaxial compression condition, a stress ratio of $q / p$ greater than 3 requires the minor principal stress $\sigma_{3}$ to be less than zero. Therefore, the clay must have cohesion to sustain the tensile stress. That a highly overconsolidated clay may possess cohesion will cause confusion, because normally consolidated clay is typically considered to be cohesionless. Meanwhile, based on the investigation of sand strength and dilatancy relationship by Taylor (1948), Schofield (2006) stated that the higher peak stress ratio of an overconsolidated clay is essentially caused by dilatancy [or interlocking in Taylor (1948)] rather than cohesion. If a straight Hvorslev envelope is used in the modeling, the zero-tension Line OF Fig. 3 needs also to be adopted to control the peak stress ratio that an overconsolidated clay can sustain (Schofield 1980). However, the discontinuous corner formed by these two lines in the $p-q$ plane may cause some numerical difficulties in constitutive modeling (see Point $F$ in Fig. 3). Note that the zero-cohesion statement is only applicable

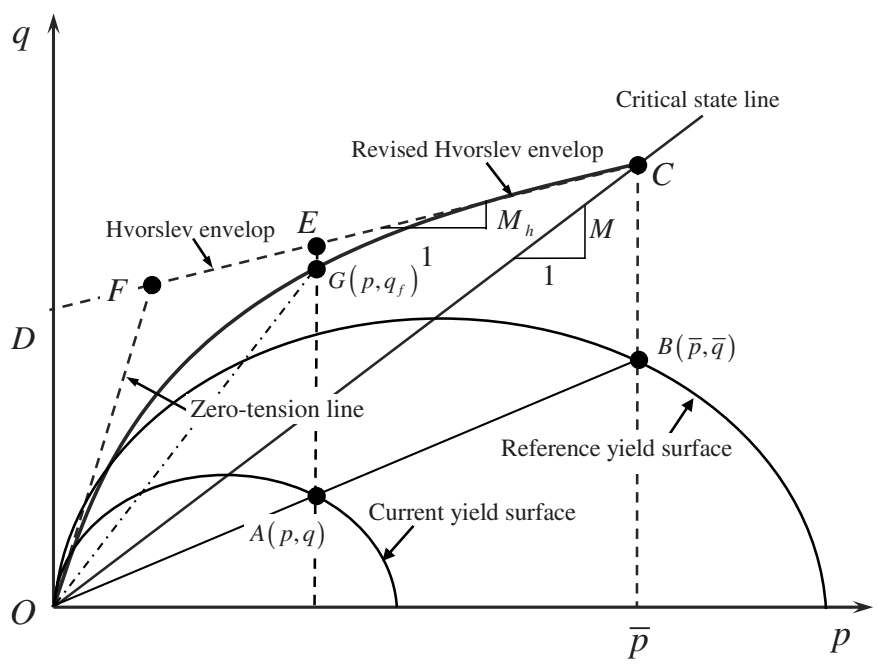

Fig. 3. Straight (Line CD) and parabolic (Line OGC) Hvorslev envelopes 

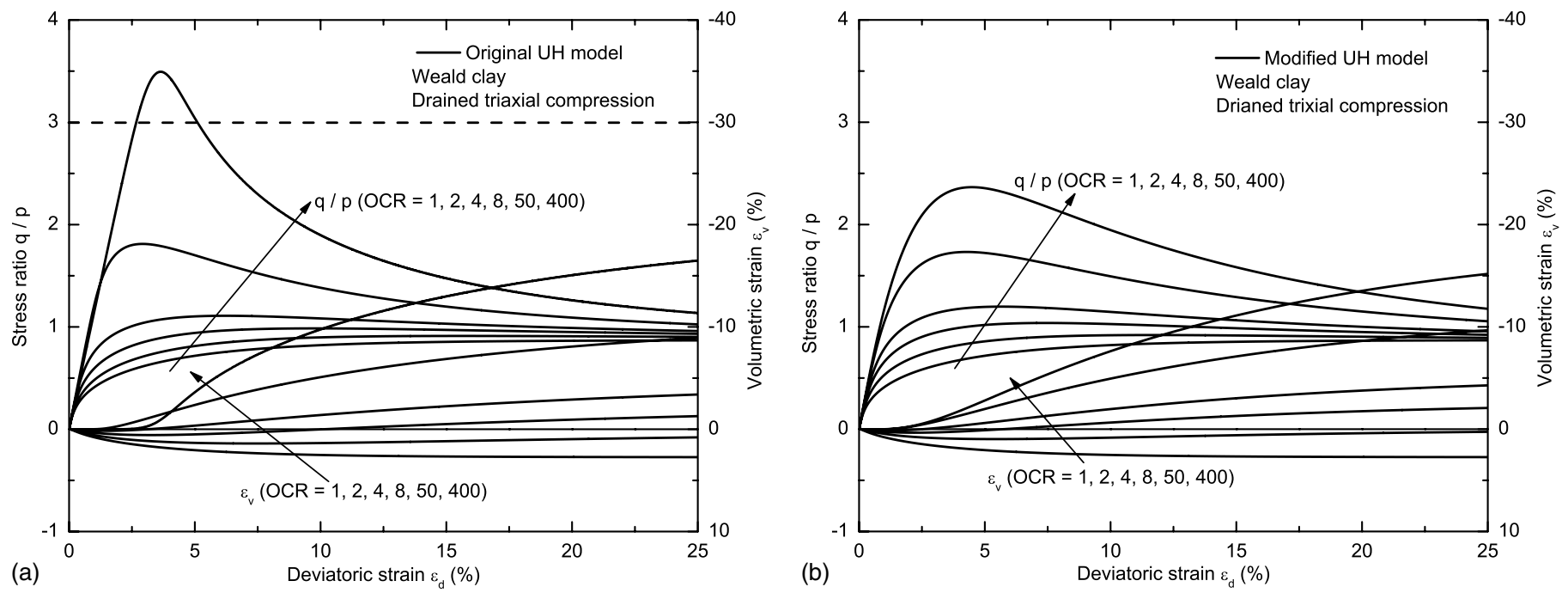

Fig. 4. Model simulations for Weald clay under drained constant-mean-stress triaxial compression using (a) the original UH model and (b) the modified UH model

to reconstituted clays being treated in the current study, whereas for artificially cemented or some structured clays true cohesion may exist because of the cementation and precipitation process.

Experimental data indicate that an appropriate strength locus for overconsolidated clays should approach the zero-tension line as the overconsolidation ratio increases to infinity. It should also intersect with the critical state line in the $p-q$ plane when the sample becomes normally consolidated (Parry 1956; Atkinson 2007). Indeed, some studies have already been done to model the peak strength of highly overconsolidated clays more realistically using a curved failure surface in the $p-q$ plane (e.g., Perry 1994; Atkinson 2007). However, practical use of these curves in constitutive modeling is rarely seen. A natural method to control the predicted peak stress ratio of highly overconsolidated clays is to use a yield/bounding surface lower than that of the yield surface of the modified Cam-clay model on the dry side with $\eta>M$ (e.g., Dafalias and Herrmann 1986). However, this method would require the introduction of additional parameters. To avoid the various complications, a parabolic Hvorslev envelope with the following expression is used to represent the failure surface of overconsolidated clays in this study:

$$
\left(q_{f}-q_{0}\right)^{2}=2 \beta\left(p-p_{0}\right)
$$

where point $\left(p_{0}, q_{0}\right)=$ vertex of the parabola; $\beta=$ parameter controlling the curvature; and Point $G\left(p, q_{f}\right)=$ a point on the parabolic Hvorslev envelope (Fig. 3). The expression for the new Hvorslev envelope can be further derived according to the following.

1. When $R=1$, the soil becomes normally consolidated. The parabolic Hvorslev envelope needs to intersect with the critical state line at Point $C(\bar{p}, M \bar{p})$. Hence, from Eq. (12) we have the following equation at this point:

$$
\left(M \bar{p}-q_{0}\right)^{2}=2 \beta\left(\bar{p}-p_{0}\right)
$$

2. The parabola also goes through the origin of the $p-q$ plane such that

$$
q_{0}^{2}=-2 \beta p_{0}
$$

3. When the overconsolidation ratio is equal to infinity at the origin, the slope of the parabola should be equal to 3 for cohesionless soils with the zero-tension cut line as its tangent.
The following equation can be obtained by differentiating Eq. (12) with respect to $p$ :

$$
\left.\left(\partial q_{f} / \partial p\right)\right|_{(0,0)}=-\beta / q_{0}=3
$$

The values of $p_{0}, q_{0}$, and $\beta$ can be readily solved by combing Eqs. (13)-(15). Eventually we obtain the following expression for the parabola:

$$
q_{f}=\sqrt{\frac{-3 M^{2} \bar{p}}{M-3}\left(p-\frac{M \bar{q}}{12(M-3)}\right)}+\frac{M \bar{q}}{2(M-3)}
$$

As $\bar{p}=p / R$ [Eq. (7)], the following equation can be obtained:

$$
q_{f}=\sqrt{36 k \frac{p}{R}\left(p+k \frac{p}{R}\right)}-6 k \frac{p}{R}
$$

where

$$
k=\frac{M^{2}}{12(3-M)}
$$

In summarizing the previous derivation, the potential failure stress ratio $M_{f}$ can be written as follows:

$$
M_{f}=\frac{q_{f}}{p}=6\left[\sqrt{\frac{k}{R}\left(1+\frac{k}{R}\right)}-\frac{k}{R}\right]
$$

Notably, not a single extra parameter other than those used in the Cam-clay models has been introduced in this new expression of $M_{f}$. With the new parabolic Hvorslev envelope, the use of such

Table 1. Model Parameters for Weald Clay

\begin{tabular}{lccccc}
\hline$M(\varphi)$ & $M_{h}$ & $\lambda$ & $\kappa$ & $\nu$ & $e_{\Gamma}$ \\
\hline $0.87\left(22.4^{\circ}\right)$ & 0.72 & 0.093 & 0.035 & 0.15 & 1.06 \\
\hline
\end{tabular}

Note: Data from Mita et al. (2004) and Muir Wood (1990). 

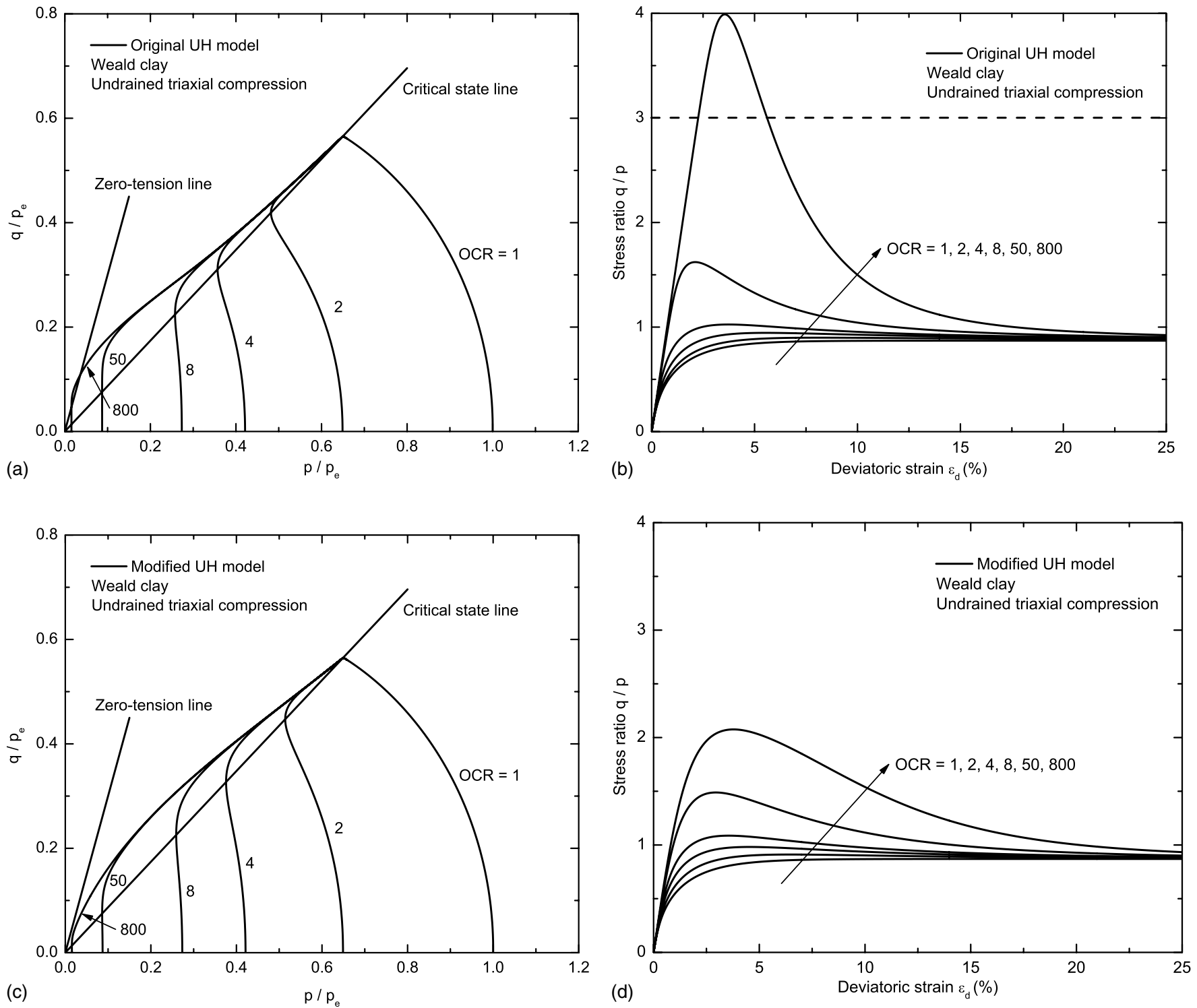

Fig. 5. Predicted responses for Weald clay under undrained triaxial compression using the original UH model [(a) and (b)] and the modified UH model $[(\mathrm{c})$ and $(\mathrm{d})]$

parameters as $M_{h}$ in Eq. (11) as in the original UH model in Yao et al. (2009) may even be avoided.

By using the new potential peak stress ratio $M_{f}$ presented in Eq. (19), the original UH model is modified, with other parts of the formulation essentially being unchanged. The entire formulation is not provided here to avoid excessive repetition. Interested readers may refer to Yao et al. (2009) for details. The performance of the modified model over the original one on the prediction of overconsolidated soils will be shown in the subsequent section.

\section{Model Comparison and Verification}

\section{Drained Triaxial Compression on Weald Clay}

To demonstrate the advantage of using the parabolic Hvorslev envelope, it is useful to make a comparison of the model response using the new formulation with the original UH model under typical loading conditions. Shown in Fig. 4 are the simulated responses obtained with the original UH model with a straight-line
Hvorslev envelope and the modified model using the parabolic envelope for the Weald clay under drained constant-mean-stress triaxial compression. The chosen model parameters shown in Table 1 are determined according to Mita et al. (2004) and Muir Wood (1990). Because the SMP criterion is used in generalizing the model to the 3D stress space, the friction angle $\varphi$ is also listed in Table 1 . Here, $e_{\Gamma}$ is the value of $e$ at $p=1 \mathrm{kpa}$ on the normal consolidation line, $p_{e}$ is the equivalent consolidation pressure defined as the mean stress on the normal compression line at the current void ratio (Muir Wood 1990), and $\varepsilon_{d}[=$ $\left.\sqrt{2 / 3\left(\varepsilon_{i j}-1 / 3 \varepsilon_{\nu} \delta_{i j}\right)\left(\varepsilon_{i j}-1 / 3 \varepsilon_{\nu} \delta_{i j}\right)}\right]$ is the deviatoric strain, with

Table 2. Model Parameters for Kaolin Clay

\begin{tabular}{lccc}
\hline$M(\varphi)$ & $\lambda$ & $\kappa$ & $\nu$ \\
\hline $1.04\left(26.3^{\circ}\right)$ & 0.14 & 0.05 & 0.2 \\
\hline
\end{tabular}

Note: Data from Dafalias and Herrmann (1986). 


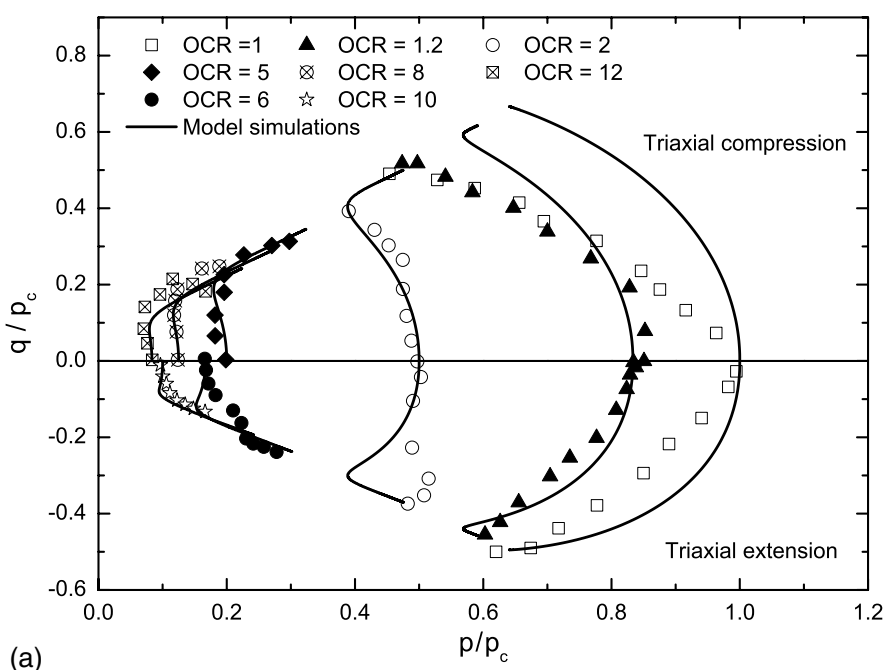

(a)

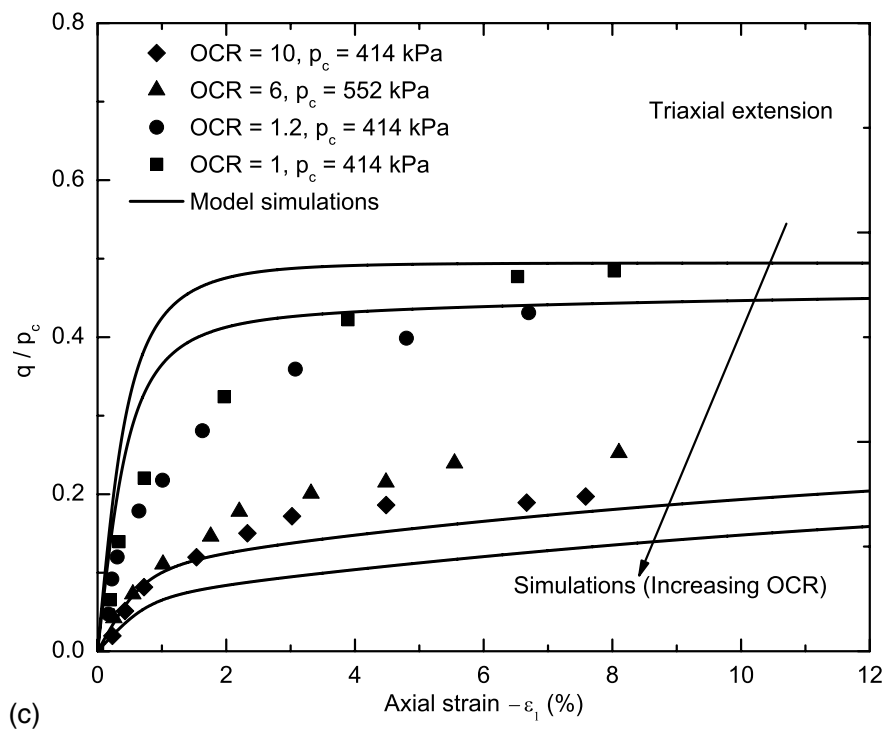

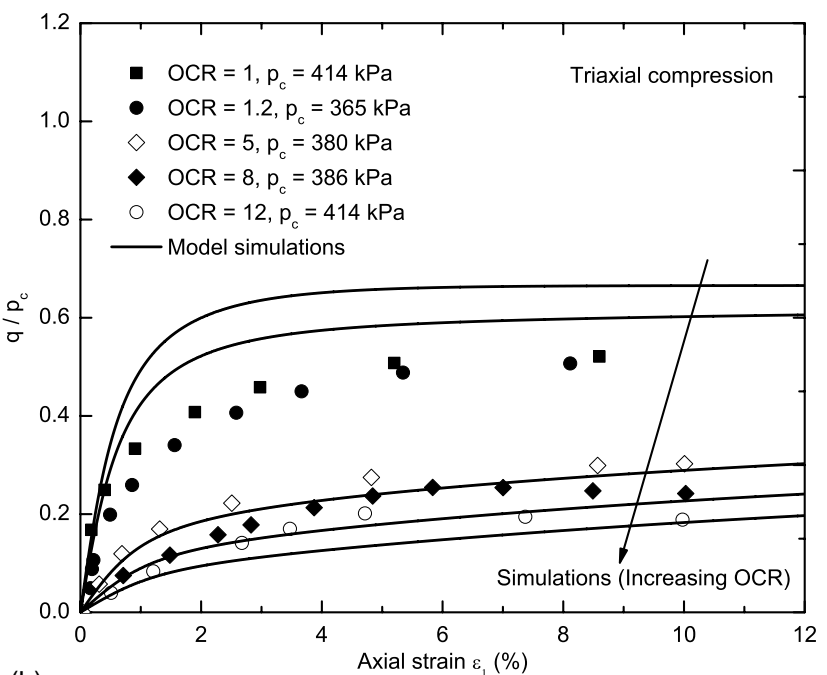

(b)

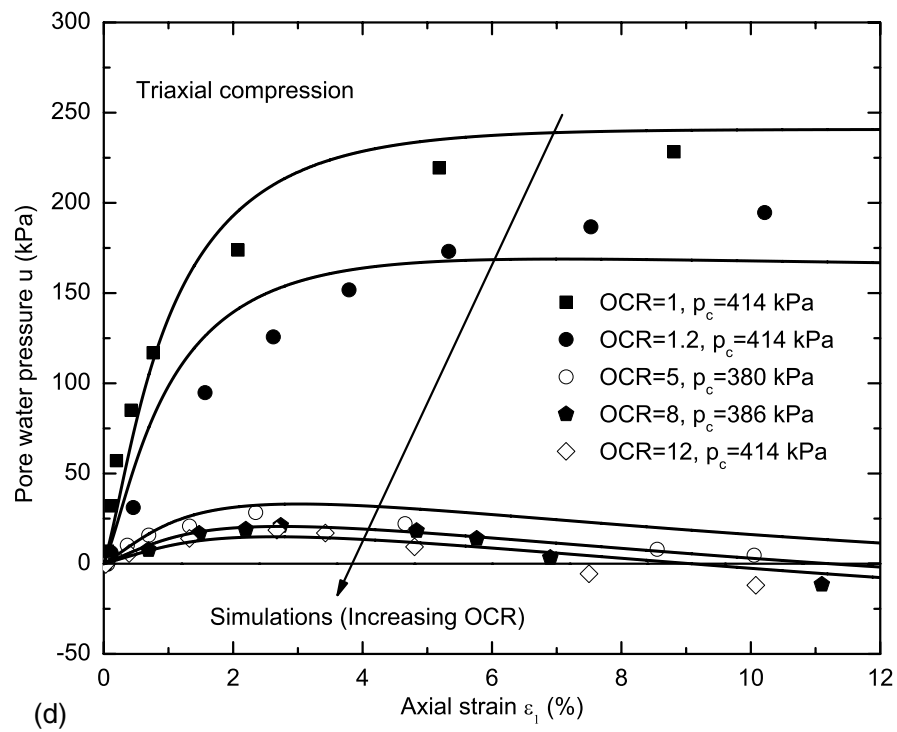

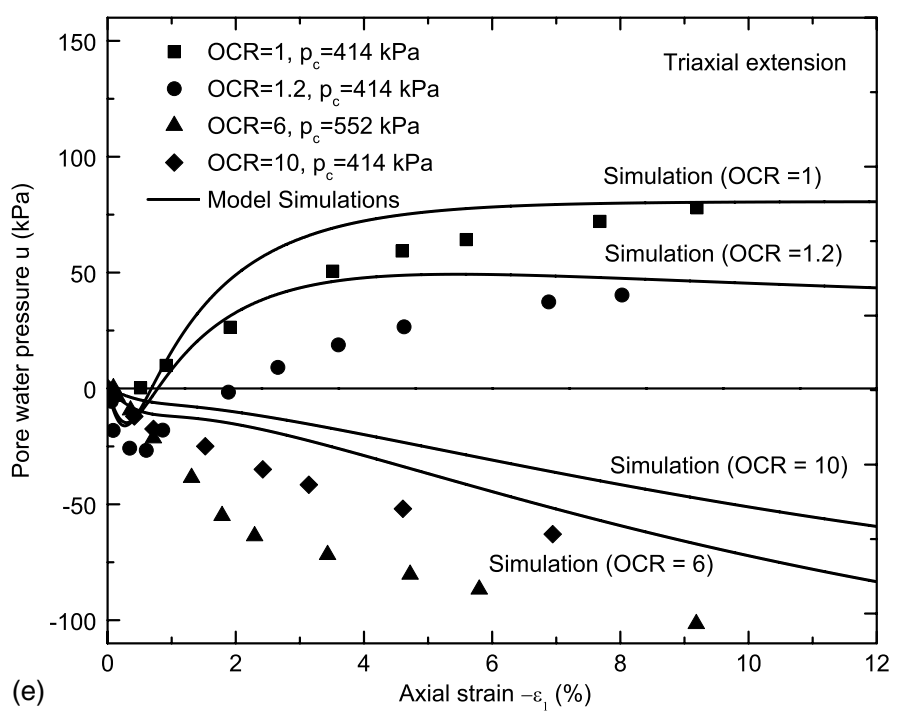

Fig. 6. Comparison of the test results on Kaolin clay (data from Stipho 1978; Banerjee and Stipho 1978, 1979) with the simulations using the modified UH model 
$\varepsilon_{i j}$ and $\varepsilon_{\nu}$ denoting the strain tensor and volumetric strain, respectively. Notably, the original UH model predicts a peak stress ratio greater than 3 when the OCR is 400, and this ratio will become even bigger if higher OCR is used. In contrast, in all cases the modified model provides reasonable predictions with no peak stress ratio exceeding 3. Meanwhile, it can be seen from the predicted $\varepsilon_{d}-\varepsilon_{\nu}$ relationships that the use of the new $M_{f}$ expressed by Eq. (19) does not have a significant influence on the model capability in describing the dilatancy behavior of clays. Only in the OCR $=400$ case does the modified UH model give slightly greater volumetric expansion than the original model at very large deviatoric strain levels.

\section{Undrained Shear on Weald Clay}

Presented in Fig. 5 is a comparison of the model predictions with the original and the new Hvorslev envelope for Weald clay under undrained shear conditions. As is seen, the predicted effective stress path by the original UH model intersects with the zero-tension line in the case of OCR $=800$ [Fig. 5(a)], and correspondingly, the peak stress ratio in this case is greater than 3 [Fig. 5(b)]. Similar to the drained case, the undrained case peak stress ratio predicted by the original UH model appears to increase steadily with the OCR of the sample. Hence, more likely the peak stress ratio will become even greater when cases with higher OCRs are examined. The UH model with the new modification, on the other hand, predicts that the predicted peak stress ratio increases with the OCR but gradually converges to 3 at high OCRs. This is evidently in better accordance with experimental results (e.g., Parry 1956; Atkinson 2007). It also is noticed that the predicted effective stress paths of the two models are very close. Evidently, the use of the new $M_{f}$ expressed by Eq. (19) does not dramatically affect the model predictions on dilatancy, as has been previously discussed. It should also be mentioned that it is hard to find clays with OCRs as high as 50 in nature. However, such high OCR values may be encountered in some boundary value problems. Figs. 4 and 5 are only used to illustrate that the modified expression for $M_{f}$ [Eq. (19)] may ensure that the predicted peak stress ratio $q / p$ for overconsolidated clays will never exceed 3, which is consistent with the statement by Schofield (2006) that reconstituted clays have no cohesion.

\section{Model Verification with Experimental Data on Kaolin Clay}

The predictive capability of the modified UH model has been further examined by experimental data on Kaolin clay as reported by Stipho (1978) and Banerjee and Stipho (1978, 1979). To begin with, it is instructive to briefly discuss the determination of model parameters. Normally, the critical state line slope $M$ is determined based on the failure stress ratio $q / p$ of normally consolidated clays in triaxial compression. The parameters $\lambda$ and $\kappa$ can be determined according to isotropic consolidation/swelling tests on a reconstituted clay. Alternatively, they can be determined based on the oedometer test results. The Poisson ratio $\nu$ controls the elastic response of a clay and can be determined empirically because the strain of a clay sample under shear is usually dominated by plastic deformation. The initial void ratio $e_{0}$ is also required in the model implementation. Hence, the location of the normal consolidation line in the $e-p$ plane, or equivalently, the value of $e_{\Gamma}$, needs to be determined.

The model parameters for Kaolin clay shown in Table 2 are the same as those used by Dafalias and Herrmann (1986). Because the location of the normal consolidation line in the $e-p$ plane is not available, the average value of the initial void ratio $e_{0} \approx 0.95$ is used (Dafalias and Herrmann 1986) in the implementation.
Fig. 6 shows a comparison between the model responses using the modified UH model (solid lines) and the experimental results (dots), wherein $\varepsilon_{1}$ denotes the axial strain.

As indicated from Fig. 6(a), the modified UH model captures the general trend of the stress paths with various OCR values. However, the model prediction is far away from the test data at $\mathrm{OCR}=1$ and 1.2 in triaxial compression. A similar discrepancy can also be seen from the $\varepsilon_{1}-q / p_{c}$ relationship for these two cases [Fig. 6(b)]. Note that the same test data have also been used by Dafalias and Herrmann (1986), and it was found that better simulations can be achieved for these two cases if a bounding surface flatter than the yield surface of the modified Cam-clay model is used. Actually, the use of a flatter yield surface has also been discussed in great detail by Banerjee and Stipho (1978), as well as by Jiang and Ling (2010). However, in doing so additional parameters have to be introduced to characterize the slenderness of the bounding surface. For the OCR $=8$ and 12 cases in triaxial compression, the predicted peak stress ratio is lower than the measured value [Fig. 6(a)]. To improve the model performance in this regard, a Hvorslev envelop of the power form as proposed by Atkinson (2007) appears to be a better option; however, this is at the cost of needing one additional parameter to describe the curvature of the failure line. As for the $\varepsilon_{1}-q / p_{c}$ relationship shown in Figs. 6(b) and $6(\mathrm{c})$, the model tends to give softer responses than the measured ones at OCR $=8$ and 12 in triaxial compression and $\mathrm{OCR}=6$ and 10 in triaxial extension. To achieve more accurate predictions, plausible improvement can be made by modifying the UH parameter to obtain a stiffer soil response at high OCR values. The predicted $\varepsilon_{1}-u$ relationship is found to compare well with the test results in triaxial compression [Fig. 6(d)]. However, in triaxial extension the peak positive pore water pressure predicted by the model appears to be higher than the testing data for OCR = 1 and 1.2, whereas the model produces relatively lower peak negative pore water pressure than the tests for OCR $=6$ and 10 [Fig. 6(e)], although the deviations are not significantly large. As a whole, the comparison shows that the modified model can reasonably well simulate the behavior of overconsolidated clays even when the OCR is high.

\section{Conclusion and Discussion}

The original UH model as proposed in Yao et al. (2009) has been modified to simulate the behavior of overconsolidated clays. The original straight Hvorslev envelope denoting the potential failure surface is replaced with a new parabolic Hvorslev envelope that is tangent to the zero-tension cutoff line at the origin of the $p-q$ plane and intersects the critical state line when a clay sample becomes normally consolidated. The performance of the new model has been compared with the original one, as well as with testing data on clays. The major conclusions from the study are summarized as follows.

1. While the use of a straight Hvorslev envelope in the UH model suffices for most practical applications, it may cause perplexing confusion in that a highly overconsolidated clay may possess cohesion while a normally consolidated one has no cohesion at all. Meanwhile, critical state soil mechanics emphasizes that higher peak stress ratios for overconsolidated clays should be interpreted as a result of dilatancy rather than cohesion. Inconsistency occurs here with a straight Hvorslev envelope. However, by using the parabolic Hvorslev envelope, it is shown the original UH model can be easily modified to describe the strength behavior of overconsolidated clays with improved satisfaction, and the aforementioned contradictions or inconsistencies can be totally eliminated. 
2. The modified UH model is simple and robust for practical use in modeling overconsolidated soils. It requires the same parameters as the Cam-clay models (four in total), which can be conveniently calibrated by routine laboratory tests. A comparison with the experimental data demonstrated that the modified UH model can capture the overall behavior of overconsolidated clays qualitatively well. With these advantages, a promising future for this new model being applied to engineering practice is foreseen.

While the proposed model has been shown to be able to capture the main features of the behavior of overconsolidated clays with a relatively small number of parameters, it has been developed for reconstituted clays with an initially isotropic fabric and isotropic stress state. In addition, some other notable limitations associated with the present model as well as potential improvements are noted as follows.

1. In the modified UH model, the major axes of the reference and current yield surfaces lie on the hydrostatic axis, which may limit its capacity for more advanced modeling. Previous studies show that a rotating yield surface in the $p-q$ plane is more appropriate to account for the effect of anisotropy on clay behavior (e.g., Sekiguchi and Ohta 1977; Anandarajah and Dafalias 1986; Whittle and Kavvadas 1994; Hashiguchi and Chen 1998). Indeed, based on the framework propose by Sekiguchi and Ohta (1977), the first writer and his coworkers have tried to model the behavior of initially $K_{0^{-}}$ overconsolidated clays using the rotated current yield surface and reference yield surface in the $p-q$ plane (Yao and Hou 2008). However, the model cannot characterize the effect of induced anisotropy because only the size of the two surfaces keeps changing with plastic deformation. However, the major axes and shape are assumed to be fixed. Indeed, further work is needed to account for proper evolution of the location and shape of the two surfaces (e.g., Anandarajah and Dafalias 1986; Whittle and Kavvadas 1994). In particular, the simple kinematic hardening rules proposed by Banerjee and Yousif (1986) may be used to improve this $K_{0}$ model performance.

2. It has also been widely recognized that the behavior of clays is strongly affect by its structure formed during the sedimentation processes (e.g., Burland 1990; Leroueil and Vaughan 1990). Although the present model is proposed for reconstituted clays, it can be used as a basis to develop models for structured clays; e.g., following the methodologies as have been used by Rouainia and Muir Wood (2000), Gajo and Muir Wood (2001), or Asaoka et al. (2000).

3. When highly overconsolidated clays are subjected to shear, shear banding or cracks are often observed (see, e.g., Palmer and Rice 1973; Saada et al. 1994; Alshibli and Akbas 2007). However, the present model is limited to predictions of continuum soil behavior only-even when strain softening occurs that is probably caused by cracks or shear banding.

\section{Acknowledgments}

This research was supported by the National Natural Science Foundation of China (Grant Nos. 11072016, 51179003, and 10872016). The writers thank Dr. W. Hou of Beihang University, China, for valuable discussions and comments on an initial version of the manuscript.

\section{References}

Alshibli, K. A., and Akbas, I. S. (2007). "Strain localization in clay: Plane strain versus triaxial loading conditions." Geotech. Geol. Eng., 25(1), $45-55$.
Anandarajah, A. M., and Dafalias, Y. F. (1986). "Bounding surface plasticity. III: Application to anisotropic cohesive soils." J. Eng. Mech., 112(12), 1292-1318.

Asaoka, A., Nakano, M., and Noda, T. (2000). "Super loading yield surface concept for highly structured soil behaviour." Soils Found., 40(2), 99-110.

Atkinson, J. (2007). "Peak strength of overconsolidated clays." Geotechnique, 57(2), 127-135.

Banerjee, P. K., and Stipho, A. S. (1978). "Associated and non-associated constitutive relations for undrained behavior of isotropic soft clays." Int. J. Numer. Anal. Methods Geomech., 2(1), 35-56.

Banerjee, P. K., and Stipho, A. S. (1979). "An elastoplastic model for undrained behavior of heavily overconsolidated clay." Int. J. Numer. Anal. Methods Geomech., 3(1), 97-103.

Banerjee, P. K., and Yousif, N. B. (1986). "A plasticity model for the mechanical behavior of anisotropically consolidated clay." Int. J. Numer. Anal. Methods Geomech., 10(5), 521-541.

Bishop, A. W. (1971). "Shear strength parameters for undisturbed and remoulded soil specimens." Proc., Roscoe Memorial Symposium, 3-58.

Burland, J. B. (1990). "On the compressibility and shear strength of natural clays." Geotechnique, 40(3), 329-378.

Dafalias, Y. F. (1986). "Bounding surface plasticity. I: Mathematical formulation and hypoplasticity." J. Eng. Mech., 112(9), 966-987.

Dafalias, Y. F., and Herrmann, L. R. (1986). "Bounding surface plasticity. II: Application to isotropic cohesive soils." J. Eng. Mech., 112(12), $1263-1291$

Dafalias, Y. F., Manzari, M. T., and Papadimitriou, A. G. (2006). "SANICLAY: Simple anisotropic clay plasticity model." Int. J. Numer. Anal. Methods Geomech., 30(12), 1231-1257.

Dafalias, Y. F., and Popov, E. P. (1977). "Cyclic loading for materials with a vanishing elastic region." Nucl. Eng. Des., 41(2), 293-302.

Drucker, D. C., and Prager, W. (1952). "Soil mechanics and plastic analysis or limit design." Q. Appl. Math., 10(2), 157-165.

Gajo, A., and Muir Wood, D. (2001). "A new approach to anisotropic, bounding surface plasticity: general formulation and simulations of natural and reconstituted clay behaviour." Int. J. Numer. Anal. Methods Geomech., 25(3), 207-241.

Gao, Z. W., Zhao, J. D., and Yao, Y. P. (2010). "A generalized anisotropic failure criterion for geomaterials." Int. J. Solids Struct., 47(22-23), $3166-3185$

Habib, P. (1953). "Influence de la variation de la contrainte principale moyenne sur la résistance au cisaillement des sols." Proc., 3rd Int. Conf. on Soil Mechanics and Foundation Engineering, 1, 131-136.

Hashiguchi, K. (1978). "Plastic constitutive equations of granular materials." Proc., US-Japan Seminar on Continuum Mechanical and Statistical Approaches in the Mechanics of Granular Materials, Aachen, Germany, S. C. Cowin and M. Satake, eds., Balkema, Rotterdam, Netherlands, 435-439.

Hashiguchi, K. (1980). "Constitutive equations of elastoplastic materials with elasticoplastic transition." J. Appl. Mech., 47(2), 266-272.

Hashiguchi, K., and Chen, Z. P. (1998). "Elastoplastic constitutive equation of soils with the subloading surface and the rotational hardening." Int. J. Numer. Anal. Methods Geomech., 22(3), 197-227.

Hashiguchi, K., and Collins, I. F. (2001). "Stress rate-elastic stretching relations in elastoplastic constitutive equations for soils." Soils Found., 41(2), 77-87.

Hill, R. (1950). Mathematical theory of plasticity, Oxford University Press, Oxford, UK.

Jiang, J., and Ling, H. I. (2010). "A framework of an anisotropic elastoplastic model for clays." Mech. Res. Commun., 37(4), 394-398.

Lade, P. V., and Duncan, J. M. (1975). "Elastoplastic stress-strain theory for cohesionless soil." J. Geotech. Eng. Div., 101(10), 1037-1053.

Leroueil, S., and Vaughan, P. R. (1990). "The general and congruent effects of structure in natural soils and weak rocks." Geotechnique, 40(3), 467-488.

Ling, H. I., Yue, D. Y., Kaliakin, V. N., and Themelis, N. J. (2002). "Anisotropic elastoplastic bounding surface model for cohesive soils." J. Eng. Mech., 128(7), 748-758.

Matsuoka, H., and Nakai, T. (1974). "Stress-deformation and strength characteristics of soil under three different principal stresses." Proc. JSCE, 232, 59-70. 
Mita, K. A., Dasari, G. R., and Lo, K. W. (2004). "Performance of a threedimensional Hvorslev-modified Cam-Clay model for overconsolidated clay." Int. J. Geomech., 4(4), 296-309.

Mróz, Z. (1967). "On the description of anisotropic workhardening." J. Mech. Phys. Solids, 15(3), 163-175.

Mróz, Z., Norris, V. A., and Zienkiewicz, O. C. (1978). "An anisotropic hardening model for soils and its application to cyclic loading." Int. $J$. Numer. Anal. Methods Geomech., 2(3), 203-221.

Mróz, Z., Norris, V. A., and Zienkiewicz, O. C. (1979). "Application of an anisotropic hardening model in the analysis of elasto-plastic deformation of soils." Geotechnique, 29(1), 1-34.

Muir Wood, D. (1990). Critical state soil mechanics, Cambridge University Press, Cambridge, UK.

Nakai, T., and Hinokio, M. (2004). "A simple elastoplastic model for normally and over-consolidated soils with unified material parameters." Soils Found., 44(2), 53-70.

Palmer, A. C., and Rice, J. R. (1973). "The growth of slip surfaces in the progressive failure of over-consolidated clay." Proc. R. Soc. London, Ser. A, 332(1591), 527-548.

Parry, R. H. G. (1956). "Strength and deformation of clay." Ph.D. thesis, Univ. of London, London.

Pender, M. J. (1978). "A model for the behaviour for overconsolidated soil." Geotechnique, 28(1), 1-25.

Perry, J. (1994). "A technique for defining non-linear shear strength envelopes, and their incorporation in a slope stability method of analysis." Q. J. Eng. Geol. Hydrogeol., 27(3), 231-241.

Pestana, J. M., Whittle, A. J., and Gens, A. (2002). "Evaluation of a constitutive model for clays and sands: Part II-clay behaviour." Int. J. Numer. Anal. Methods Geomech., 26(11), 1123-1146.

Prashant, A., and Penumadu, D. (2004). "Effect of intermediate principal stress on overconsolidated Kaolin clay." J. Geotech. Geoenviron. Eng., 130(3), 284-292.

Roscoe, K. H., and Burland, J. B. (1968). "On the generalized stress-strain behavior of wet clay." Engineering plasticity, J. Heyman and F. A. Leckie, eds., Cambridge University Press, Cambridge, UK, 535-609.

Roscoe, K. H., Schofield, A. N., and Thurairajah, A. (1963). "Yielding of clays in states wetter than critical." Geotechnique, 13(3), 211-240.

Roscoe, K. H., Schofield, A. N., and Wroth, C. P. (1958). "On the yielding of soils." Geotechnique, 8(1), 22-53.

Rouainia, M., and Muir Wood, D. (2000). "A kinematic hardening constitutive model for natural clays with loss of structure." Geotechnique, 50(2), 153-164.
Saada, A. S., Bianchini, G. F., and Liang, L. (1994). "Cracks, bifurcation and shear bands propagation in saturated clays." Geotechnique, 44(1), $35-64$.

Schofield, A. N. (1980). "Cambridge geotechnical centrifuge operations." Geotechnique, 30(3), 227-268.

Schofield, A. N. (2006). "Interlocking, and peak and design strengths." Geotechnique, 56(5), 357-358.

Schofield, A. N., and Wroth, C. P. (1968). Critical state soil mechanics, McGraw-Hill, London.

Sekiguchi, H., and Ohta, K. (1977). "Induced anisotropy and time dependency in clays." Proc., 9th Int. Conf. on Soil Mechanics and Foundation Engineering, Special Session 9, Tokyo, 229-238.

Stipho, A. S. A. (1978). "Experimental and theoretical investigation of the behavior of anisotropically consolidated kaolin." Ph.D. thesis, Univ. College of Cardiff, Cardiff, UK.

Taylor, D. W. (1948). Fundamentals of soil mechanics, Wiley, New York.

Whittle, A. J., and Kavvadas, M. J. (1994). "Formulation of MIT-E3 constitutive model for overconsolidated clays." J. Geotech. Eng., 120(1), 173-198.

Wroth, C. P., and Houlsby, G. T. (1985). "Soil mechanics: Property characterization and analysis procedures." Proc., 11th Int. Conf. on Soil Mechanics and Foundation Engineering, Vol 1, San Francisco, 1-55.

Yao, Y. P., and Hou, W. (2008). "A unified hardening model for $K_{0}$ overconsolidated clays." Chin. J. Geotech. Eng., 30(3), 316-322 (in Chinese)

Yao, Y. P., Hou, W., and Zhou, A. N. (2009). "UH model: Threedimensional unified hardening model for overconsolidated clays." Geotechnique, 59(5), 451-469.

Yao, Y. P., Lu, D. C., Zhou, A. N., and Zou, B. (2004). "Generalized nonlinear strength theory and transformed stress space." Sci. China, Ser. E: Technol. Sci., 47(6), 691-709.

Yao, Y. P., Matsuoka, H., and Sun, D. A. (1999). "A unified elastoplastic model for clay and sand with SMP criterion." Proc., 8th Australia-New Zealand Conf. on Geomechanics, Hobart, Australia, 2, 997-1003.

Yao, Y. P., and Sun, D. A. (2000). "Application of Lade's criterion to Cam-clay model.” J. Eng. Mech., 126(1), 112-119.

Yao, Y. P., Zhou, A. N., and Lu, D. C. (2007). "Extended transformed stress space for geomaterials and its application." J. Eng. Mech., 133(10), $1115-1123$.

Yu, H. S. (1998). "CASM: A unified state parameter model for clay and sand." Int. J. Numer. Anal. Methods Geomech., 22(8), 621-653. 